\title{
High throughput RNase protection assay
}

\author{
Vladimir N. Mironov, Marc Van Montagu* and Dirk Inzé1
}

\author{
Laboratorium voor Genetica and ${ }^{1}$ Laboratoire associé de l'Institut National de la Recherche Agronomique \\ (France), Universiteit Gent, K.L. Ledeganckstraat 35, B-9000 Gent, Belgium
}

Received May 5, 1995; Revised and Accepted July 19, 1995

Since its development in 1983 (1), RNase protection assay (RPA) has become one of a few standard techniques for RNA analysis. The procedure is based on the hybridization of the analyzed RNA to a radioactively labelled RNA probe with subsequent digestion of unhybridized RNA with single-strand-specific nucleases, typically a combination of RNases $A$ and $T 1 \quad(2,3)$. The hybridization is traditionally performed in a formamide-containing buffer. In that case, hybridization is carried out overnight and in combination with the subsequent overnight exposure the procedure takes 2 days to be completed. Given the short life time of high-specific-activity RNA probes, just very few RPAs can be performed consecutively once a probe is prepared. The aim of this work was to streamline the standard RPA procedure to so that it can be easily accomplished during a regular working day without compromising either sensitivity or quality.

We explored the possibility to enhance RPAs throughput by shortening the hybridization time. It is well known that hybridization in the presence of formamide is quite slow, the reaction constant being 12-fold lower compared to that of the aqueoussolution hybridization in case of RNA-DNA interaction (4). The formamide-containing buffer was introduced originally for kinetic analysis of RNA-DNA hybridization, for which its application was justified mainly by the possibility to preclude the competing DNA-DNA hybridization (4). This is clearly not relevant for RPA. So, we expected the hybridization time to be considerably reduced by eliminating the formamide from the hybridization buffer and even further by increasing the salt concentration to $1 \mathrm{M}$ in the buffer. On the assumption that kinetics of RNA-RNA hybridization are similar to those of RNA-DNA hybridizations, the total gain in the hybridization rate could be estimated as $\sim 20$-fold $(4,5)$. The results presented in Figure $1 \mathrm{~A}$ confirm our expectation. The comparison was performed in conditions corresponding both to the second-order kinetics (lanes 1 and 2) and to the pseudo-first-order kinetics (lanes 3 and 4). In both cases, hybridization at $80^{\circ} \mathrm{C}$ in the absence of formamide (PES buffer in Fig. 1) for 70 min produced slightly stronger signals than the conventional procedure (STD buffer in Fig. 1). Despite the elevated hybridization temperature, no signs of excessive RNA degradation can be detected as compared with the standard procedure, apparently due to the short incubation time. When hybridization was allowed to proceed in both buffers for the same time the signals obtained with the standard buffer were consistently several-fold lower (data not shown).

Next, we assessed the possibility to enhance the hybridization rate further. Cetyltrimethylammonium bromide (CTAB) was
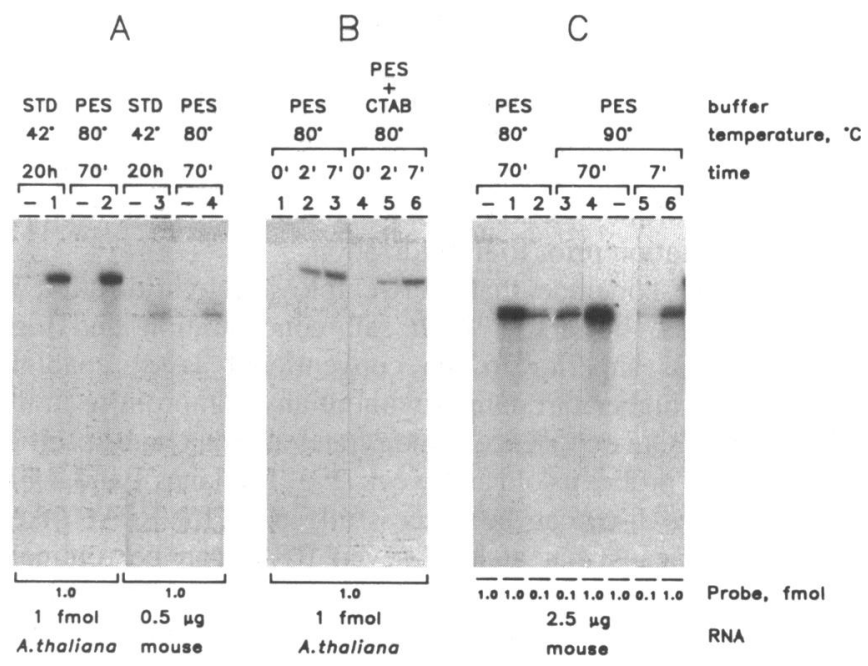

Figure 1. Application of high temperature RNA-RNA hybridization to RPA. The radioactive probes (specific activity $744 \mathrm{Ci} / \mathrm{mmol}$ ) were synthesized by in vitro transcription of cloned fragments of either Arabidopsis thaliana actin (8) or mouse $\beta$-actin (9) genes in the presence of [ ${ }^{32}$ P]CTP (Amersham, Aylesbury, $\mathrm{UK}$ ) and were used to probe in vitro synthesized A.thaliana actin RNA (303 nt protected) and total mouse liver RNA ( $250 \mathrm{nt}$ protected), respectively. In vitro transcription reactions with T7 and SP6 RNA polymerases were performed using the kits manufactured by Promega (Madison, WI, USA). The assays were done with RPA II TM kit (Ambion, Austin, TX, USA) either according to the manufacturer's instructions or substituting PES for the hybridization buffer. Unless indicated, the hybridization reactions were performed in $10 \mu$ with 1 fmol of the probes. Upon hybridization the samples were digested with RNase A $(1.5 \mu \mathrm{g} / \mathrm{ml})$ and RNase $\mathrm{T} 1(30 \mathrm{U} / \mathrm{ml})$ at room temperature for $30 \mathrm{~min}$. The amount and kind of the probed RNA are indicated at the bottom of the figure. The negative controls (lanes marked with a hyphen) contained $2.5 \mu \mathrm{g}$ of yeast tRNA. (A) High temperature hybridization in PES as compared with hybridization in the conventional STD buffer at low temperature under conditions corresponding to the second-order kinetics (lanes 1 and 2) or the pseudo-first-order kinetics (lanes 3 and 4). (B) RNA-RNA hybridization in the presence of $1 \mathrm{mM}$ CTAB. (C) Comparison of RNA-RNA hybridization at 90 versus $80^{\circ} \mathrm{C}$. Abbreviations: STD, $80 \%$ formamide/ $0.1 \mathrm{M}$ Na-citrate $(\mathrm{pH}$ 6.4)/0.3 M Na-acetate/1 mM EDTA; PES, 25 mM Pipes (pH 6.8)/1 M NaCl/1 mM EDTA.

reported to increase the rate of DNA-DNA reassociation $\sim 400$-fold when present at $1 \mathrm{mM}$ concentration (6). Therefore, we examined the possible effect of $1 \mathrm{mM}$ CTAB on RNA-RNA hybridization but failed to find any acceleration in the conditions used (Fig. 1B). Subsequently, attempts were made to optimize the

\footnotetext{
${ }^{*}$ To whom correspondence should be addressed
} 
hybridization temperature. In the absence of reliable kinetics data on RNA-RNA hybridization, the choice of $80^{\circ} \mathrm{C}$ as the hybridization temperature was unavoidably arbitrary. The results presented in Figure 1C demonstrate that indeed hybridization at $90^{\circ} \mathrm{C}$ produced considerably stronger signals (1.4- and 2.0-fold for reactions containing 1 and $0.1 \mathrm{fmol}$ of the probe, respectively) as determined by scanning with a PhosphorImager (Molecular Dynamics, Sunnyvale, CA, USA). Rough estimation of the rate constant for RNA-RNA hybridization at $90^{\circ} \mathrm{C}$ based on the data presented in Figure $1 \mathrm{C}$ gives a value close to $7 \times 10^{6} \mathrm{M}^{-1} \mathrm{~s}^{-1}$, corresponding very well to the rate constant calculated for DNA-DNA reassociation at the same salt concentration and optimal temperature (7). The extent of hybridization calculated on this basis is expected to be 94 and $25 \%$ for lane 4 and lanes 3 and 6 , respectively.

Elimination of formamide from the hybridization buffer not only shortens the hybridization time but also reduces the time for sample preparation because in this case the buffer constitutes as little as $30 \%$ of the reaction volume, so that there is no need for RNA precipitation prior to hybridization.

Finally, we conclude that RPA-employing hybridization in formamide-free buffers at high salt concentration and high temperature is superior to the conventional assay, enabling considerably higher throughput without any compromise in the signal quality. Our experience demonstrates also that high-specificactivity RNA probes as old as 1 week (Fig. 1A, lanes 1 and 2 and Fig. 1C, lanes 1-6) can be successfully used for RPA. Taken together, it means that at least seven RPAs can be routinely performed in succession with the same probe. The use of formamide-less hybridization buffers should entail also additional reproducibility to RPA, because nucleic acid duplex stability is less dependent on the GC content in aqueous solutions as compared with the high concentrated formamide solutions (4). The described streamlined procedure is applicable to RNA of different origin, including total RNA from plants and animals.

\section{ACKNOWLEDGEMENTS}

This work was supported by grants from the Belgian Program on Interuniversity Poles of Attraction (Prime Minister's Office, Science Policy Programming, \#38) and in part by the International Human Frontier Science Program (RG-434/94M) and the European Communities' BIOTECH Program, as part of the Project of Technological Priority 1993-1996. V.M. is indebted to the European Environmental Research Organization for a post-doctoral fellowship. D.I. is a Research Director of the Institut National de la Recherche Agronomique (France).

\section{REFERENCES}

1 Zinn,K., DiMaio,D. and Maniatis,T. (1983) Cell, 34, 865-879.

2 Ausubel,F.M., Brent,R., Kingston,R.E., Moore,D.D., Seidman,J.G., Smith,J.A. and Struhl,K. (1987) Current Protocols in Molecular Biology 1987-1988. Greene Publishing Associates \& Wiley-Interscience, NY.

3 Sambrook,J., Fritsch,E.F. and Maniatis,T. (1989) Molecular Cloning: A Laboratory Manual, 2nd ed. Cold Spring Harbor Laboratory Press, Cold Spring Harbor, NY.

4 Casey,J. and Davidson,N. (1977) Nucleic Acids Res., 4, 1539-1552.

5 Van Ness,J. and Hahn,W.E. (1982) Nucleic Acids Res., 10, 8061-8077.

6 Pontius,B.W. and Berg,P. (1991) Proc. Natl. Acad. Sci. USA, 88, 8237-8241.

7 Britten,R.J., Graham,D.E. and Neufeld,B.R. (1974) Methods Enzymol., 29, $363-418$.

8 Nairn,C.J., Winesett,L. and Ferl,R.J. (1988) Gene, 65, 247-257.

9 Alonso,S., Minty,A., Bourlet,Y. and Buckingham,M. (1986) Mol. Evolution, 23, 11-22. 